American Journal of Applied Sciences 9 (10): 1538-1541, 2012

ISSN 1546-9239

(C) 2012 Science Publication

\title{
Design of Pass Band Filter in Hybrid Architecture Planar/Non-Radiative Dielectric Waveguide Integration Technology
}

\author{
Harizi Hanen and Gharssallah Ali \\ Unit of Research Circuits and Electronics Systems \\ High Frequency, Faculty of Science, University El ManarTunis, Tunisia
}

\begin{abstract}
Problem statement: The expansion of RF, microwave and millimeter devices has revolutionized today's ommunication and sensor systems. Low-cost, high-performance and mass producible millimeter wave technologies are vital for commercial broadband systems. Challenging issues are commonly faced in the design of low-loss integrated circuits for example high-Q band pass filter, which the planar technique is fundamentally limited in performance. Approach: In this study, we present a design of a nonradiative dielectric waveguide band pass filter based on hybrid architecture of micro strip line and non-radiative dielectric waveguide. Results: The simulation with High Frequency Structure Simulator (HFSS) three dimensional analyses is presented. Conclusion: The non radiative dielectric resolves most of the drawbacks of dielectric waveguide in connection with the radiation loss.
\end{abstract}

Key words: Non-Radiative Dielectric (NRD), Non Radiative Perforated Dielectric (NRPD), Substrate Integrated Non Radiative Dielectric (SINRD), Engraved Non-Radiative Dielectric waveguide (ENRD), High Frequency Structure Simulator (HFSS)

\section{INTRODUCTION}

A non radiative dielectric waveguide is currently interesting filter types due to their high $\mathrm{Q}$ at low cost technology for fabrication and compatibility with other technology. Hence their electromagnetic models are still under research and therefore not easy accessible. This study aims to provide circuit designers with accurate, easy determinable for a pass band filter.

Proposed by Yoneyama and Nishida (1981) NonRadiative Dielectric (NRD) guide circuits is nowadays a well-known technology for various millimeter wave applications (Yoneyama, 2009; Yoneyama and Nishida, 1984). Subsequently, Bacha has proposed the model of a hybrid integration of NRD-waveguide and micro strip line (Bacha and Wu 1998a; 1998b). Indeed, basic features and applications of the NRD-guide had been investigated by different research. However, several techniques were proposed, Grigoropoulos and Young present a Non Radiative Perforated Dielectric (NRPD) in (Grigoropoulos and Young, 2003); Cassivi and Wu (2004) introduce the Substrate Integrated Non Radiative Dielectric (SINRD). Other scheme of design called Engraved Non-Radiative Dielectric waveguide (ENRD), proposed to reduce the problem of alignment and mechanical tolerances in fabrication of NRD components, this design was described in (Cassivi et $a l ., 2000 ; 2002)$.

\section{MATERIALS AND METHODES}

Its basic component, the NRD waveguide, consists of a rectangular-section dielectric rod (height a, width $\mathrm{b}$, permittivity $\varepsilon_{\mathrm{r} 1}$ ) sandwiched between two conducting plates that are at a distance apart less than half the freespace wavelength 20 (Fig. 1).

The required distance between the two metallic plates of NRD wave guide is computed using the following relation:

$$
\mathrm{a}<\frac{\lambda_{0}}{\sqrt[2]{\varepsilon_{\mathrm{r}}}}
$$

where, $\lambda_{0}$ the free-space wavelength $\varepsilon_{\mathrm{r}}$ the relative dielectric constant.

The hybrid architecture planar/NRD waveguide integration geometry consist of a micro strip line deposited on the top of ground plane which is one of the two parallel metallic plates of the NRD wave guide. The coupling between the two dissimilar structures is achieved though apertures that are made in the common ground plane. The aperture orientation defines essentially the operating mode in the NRD wave guide.

Corresponding Author: Harizi Hanen, Unit of Research Circuits and Electronics Systems High Frequency, Faculty of Science, University El ManarTunis, Tunisia 


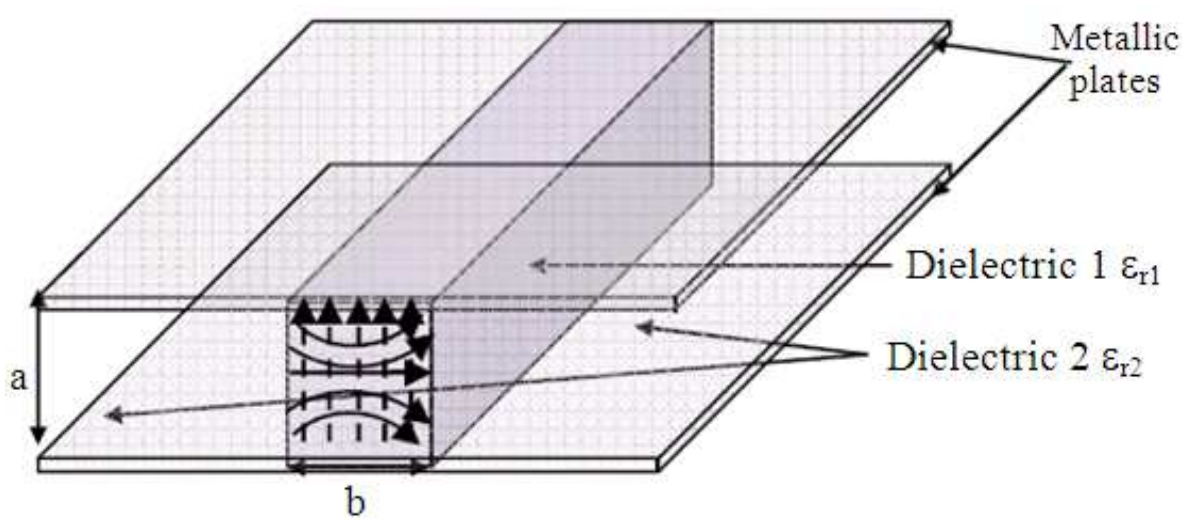

Fig. 1: General structure of NRD waveguide and the distribution of the electric and magnetic fields $\rightarrow$ Electrical Field $\rightarrow$ Magnetic Field

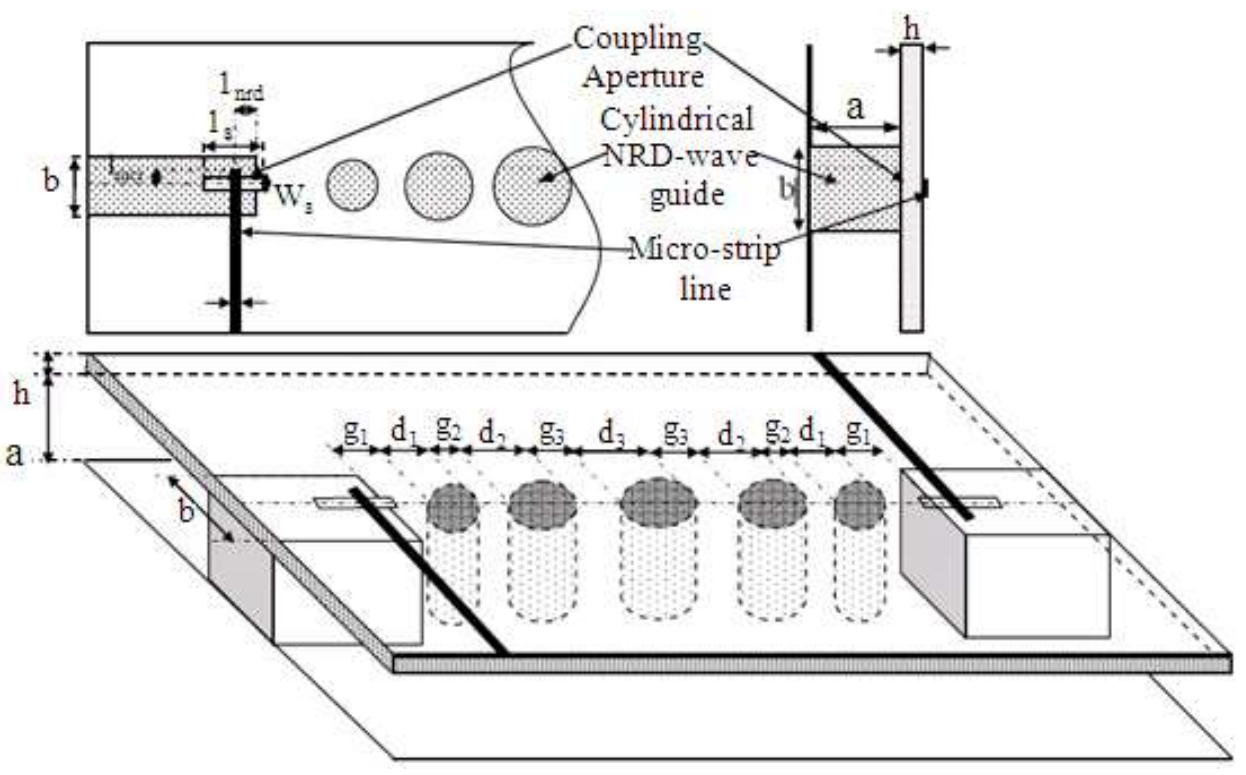

Fig. 2: Structure design of cylindrical NRD waveguide

The proposed structure of a design of pass band filter in hybrid architecture planar/NRD is presented in Fig 2. The filter is composed of a series of cylindrical dielectric resonators with a height and different diameter $\mathrm{d}_{\mathrm{i}}$, coupled by air gaps of length $\mathrm{g}_{\mathrm{i}}$.

The micro strip line is made of Rogers RT/Duroid 5880 dielectric substrate $\varepsilon_{\mathrm{r}}=2.2$ and thickness $\mathrm{h}=$ $0.254 \mathrm{~mm}$ and the width of $\mathrm{w}_{\mathrm{mcr}}=0.711 \mathrm{~mm}$. The slot size have a length $1_{\mathrm{s}}=5.842 \mathrm{~mm}$ and a width $\mathrm{w}_{\mathrm{s}}=0.508$ $\mathrm{mm}$ and the position of the slot is given by the parameters $1_{\mathrm{mcr}}=1.458 \mathrm{~mm}$ and $1_{\mathrm{nrd}}=2.616 \mathrm{~mm}$.
The NRD wave guide has a width $b=4.267 \mathrm{~mm}$ and a height $\mathrm{a}=4.572 \mathrm{~mm}$ and it's made of Polyflon Nor CALD dielectric substrate $\varepsilon_{\mathrm{r}}=2.55$.

An absorbing boundary condition is applied in reducing our computional window for this unbounded structure so an electrical rectangular box is simulated.

The Fig. 2 shows the configuration of the gap-coupled cylindrical NRD wave guide filter with geometrical dimensions $\mathrm{d}_{1}=5.705 \mathrm{~mm}, \mathrm{~d}_{2}=5.928 \mathrm{~mm}, \mathrm{~d}_{3}=5.957$ $\mathrm{mm}$ and $\mathrm{g}_{1}=1.211 \mathrm{~mm}, \mathrm{~g}_{2}=2.651 \mathrm{~mm}, \mathrm{~g}_{3}=3.199 \mathrm{~mm}$. 


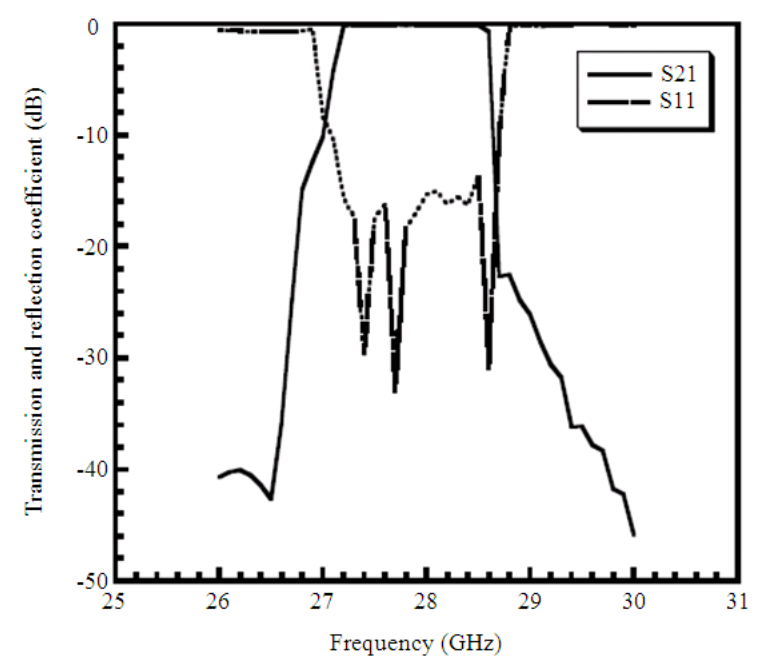

(a)

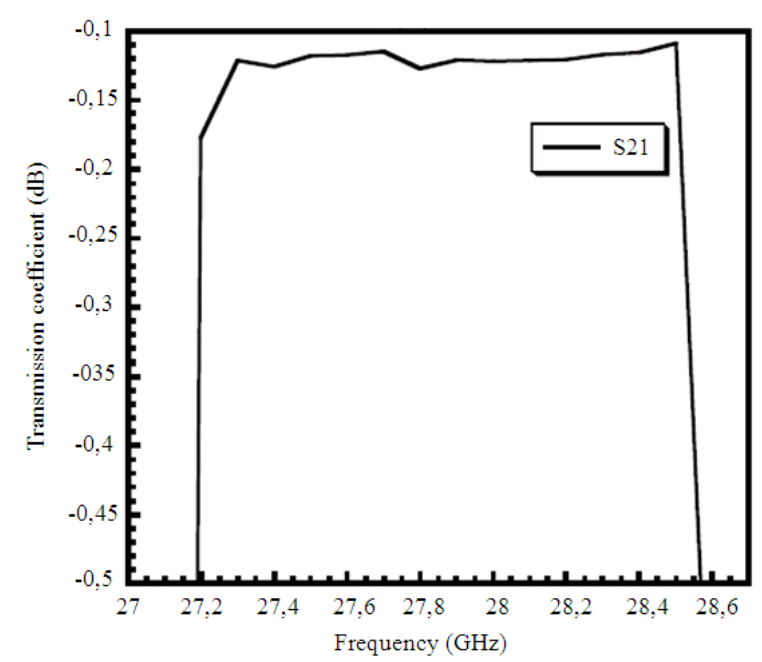

(b)

Fig. 3: Simulation result of the pass band filter with the cylindrical NRD wave guide (a) Scattering parameters (b) The ripple level in the pass band

\section{RESULTS}

This designed filter is simulated using the High Frequency Structure Simulator (HFSS) based on finite element method. Simulated filter response is shown in Fig. 3.

\section{DISCUSION}

This band pass filter has been designed for the center frequency $\mathrm{f}_{0}=28 \mathrm{GHz}$ and the bandwidth of
$5.14 \%$. The ripple level in the pass band is higher than the assumed- $0.12 \mathrm{~dB}$ value and falls down to $-0.15 \mathrm{~dB}$. Equally, the return losses in the pass band are below$15 \mathrm{~dB}$ level, except for one point where they reach the value of $-13.6 \mathrm{~dB}$.

The- $0.12 \mathrm{~dB}$ pass band is equal $3.63 \%\left(\mathrm{f}_{1}=27.5\right.$ $\mathrm{GHz}$ and $\mathrm{f}_{2}=28.5 \mathrm{GHz}$ ).

The quality factor $Q$ of a filter is a measure of how sharply the performance characteristics transition between pass band and out-of-band behavior.

$$
\mathrm{Q}=\frac{\mathrm{f}_{0}}{\Delta \mathrm{f}}
$$

Therefore, the quality factor $\mathrm{Q}$ of the band pass filter in hybrid architecture planar/NRD waveguide integration technology at frequency as high as $28 \mathrm{GHz}$ is equal to 19.5 .

\section{CONCLUSION}

The NRD-guide band pass filter in hybrid architecture planar/NRD waveguide integration technology design has been described. Numerical simulation of an entire filter structure have shown that the design has met the specification of an pass band filter in a high frequency and the presented method can be used as a fast, simple and accurate way to design NRD-wave guide filters given its ability of integration with other elements of the circuit.

\section{REFERNCES}

Yoneyama, T. and S. Nishida, 1981. Nonradiative dielectric waveguide for millimeter-wave integrated circuits. IEEE Trans. Microwave Theory Technol., 29: 1190-1981. DOI: 10.1109/TMTT.1981.1130529

Yoneyama, T., 2009. Recent advances in millimeterwave NRD-guide circuits. IEICE Trans. Elec., E92: 1106-1110.

Yoneyama, T. and S. Nishida, 1984. Nonradiative dielectric waveguide. 11: 61-98.

Bacha, A. and K. Wu, 1998a. Toward an optimum design of NRD-guide and microstrip-line transition for hybrid-integration technology. IEEE Trans. Microwave Theory Technol. 46: 1796-1800. DOI: $10.1109 / 22.734585$

Bacha, A. and K. Wu, 1998b. LSE-mode balun for hybrid integration of NRD-guide and microstrip line. IEEE Microwave Guided wave letters, 5: 199201. DOI: $10.1109 / 75.668729$ 
Grigoropoulos, N. and P.R. Young, 2003. Low cost non radiative perforated dielectric waveguide. Proeceedings of the 33rd European Conference on Microwave, Oct. 7-9, IEEE Xpolre Press, pp: 439442. DOI: 10.1109/EUMC.2003.1262317

Cassivi, Y. and K. Wu, 2004. Substrate integrated nonradiative dielectric waveguide. IEEE Microw. Wireless Compon. Lett., 14: 89-91. DOI: 10.1109/LMWC.2004.824808
Cassivi, Y., D. Deslandes and K. Wu, 2000. Engraved NRD-guide for millimeter-wave integrated circuits. IEEE MTT-S Int. Microwave Symp. Dig., 2: 605608. DOI: 10.1109/MWSYM.2000.863257

Cassivi, Y., D. Deslandes and K. Wu, 2002. Design considerations of engraved NRD Guide for millimeter-wave integrated circuits. IEEE Trans. Microwave Theory Technol., 50: 165-171. DOI: 10.1109/22.981261 